\title{
Progressive Multifocal Leukoencephalopathy Associated with Belimumab in a Patient with Systemic Lupus Erythematosus
}

CHARLOTTE LEBLANC-TRUDEAU, MD; ARIEL MASETTO, MD, Department of Rheumatology; CHRISTIAN BOCTI, MD, FRCPC, Department of Neurology, University of Sherbrooke, Sherbrooke, Quebec, Canada. Address correspondence to Dr. C. Leblanc-Trudeau, 3001 12th Ave. North,

Sherbrooke, Quebec J1H 5N4, Canada. E-mail: charlotte.leblanc-trudeau@usherbrooke.ca. J Rheumatol 2015;42:551-2; doi:10.3899/jrheum.140577

Systemic lupus erythematosus (SLE) and its treatment have been associated with progressive multifocal leukoencephalopathy (PML) ${ }^{1}$. We report a case of PML in a 58-year-old woman with SLE treated with belimumab, a biological therapy approved in 2011 for refractory SLE ${ }^{2}$. To the best of our knowledge, to date, 1 other such case has been described in the literature ${ }^{3}$. There was no case of PML described in the trials for this drug ${ }^{4}$.

The patient, diagnosed with SLE in 1978 and stable under hydroxychloroquine, presented in October 2012 with arthritis, rash, thrombopenia, and anemia. Mycophenolate mofetil (MMF) $1500 \mathrm{mg}$ bid and prednisone $10 \mathrm{mg}$ were introduced. In January 2013, her SLE was still active. Belimumab was started with a good clinical response. In
July 2013, she presented with a 3-week history of fatigue, apathy, and aphasia. Biological investigations were normal. Brain magnetic resonance imaging (MRI) showed large confluent white matter hyperintensities (Figure 1). A positive PCR of John Cunningham virus in the patient's cerebrospinal fluid confirmed the diagnosis of PML. After interruption of all immunosuppressive medication, we observed an initial neurological deterioration, probably explained by the immunological reconstitution phenomena. A second MRI showed increased diffuse white matter edema (Figure 2). During the third week, the patient progressively got better. One year later, a moderate aphasia and executive function deficits still persist, rendering her unable to lead an independent life.

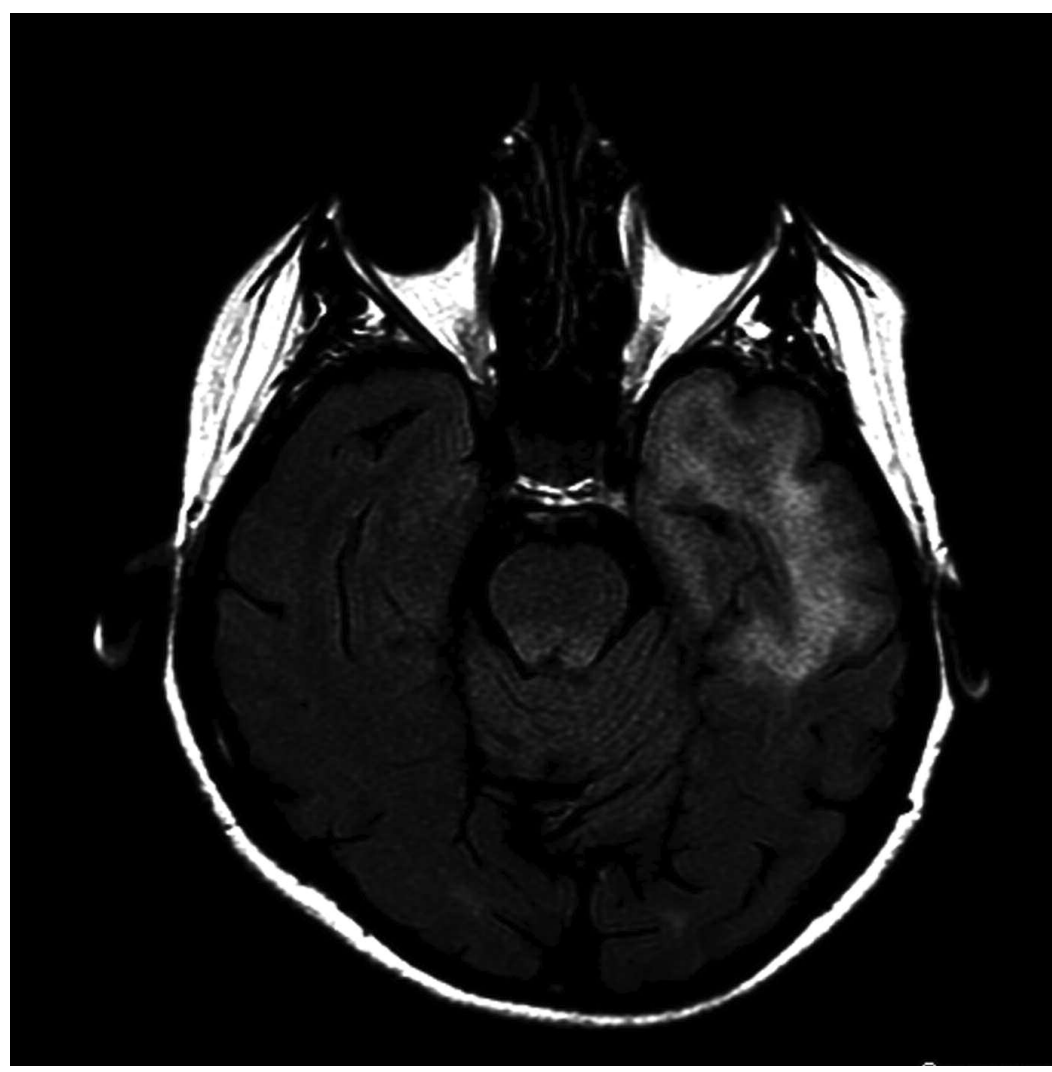

Figure 1. Brain MRI showing extensive and confluent white matter hyperintensities on FLAIR in the left temporal and frontal lobes, and amygdalohippocampic and insular regions. MRI: magnetic resonance imaging; FLAIR: fluid attenuated inversion recovery.

$$
\text { Personal non-commercial use only. The Journal of Rheumatology Copyright ( }) \text { 2015. All rights reserved. }
$$




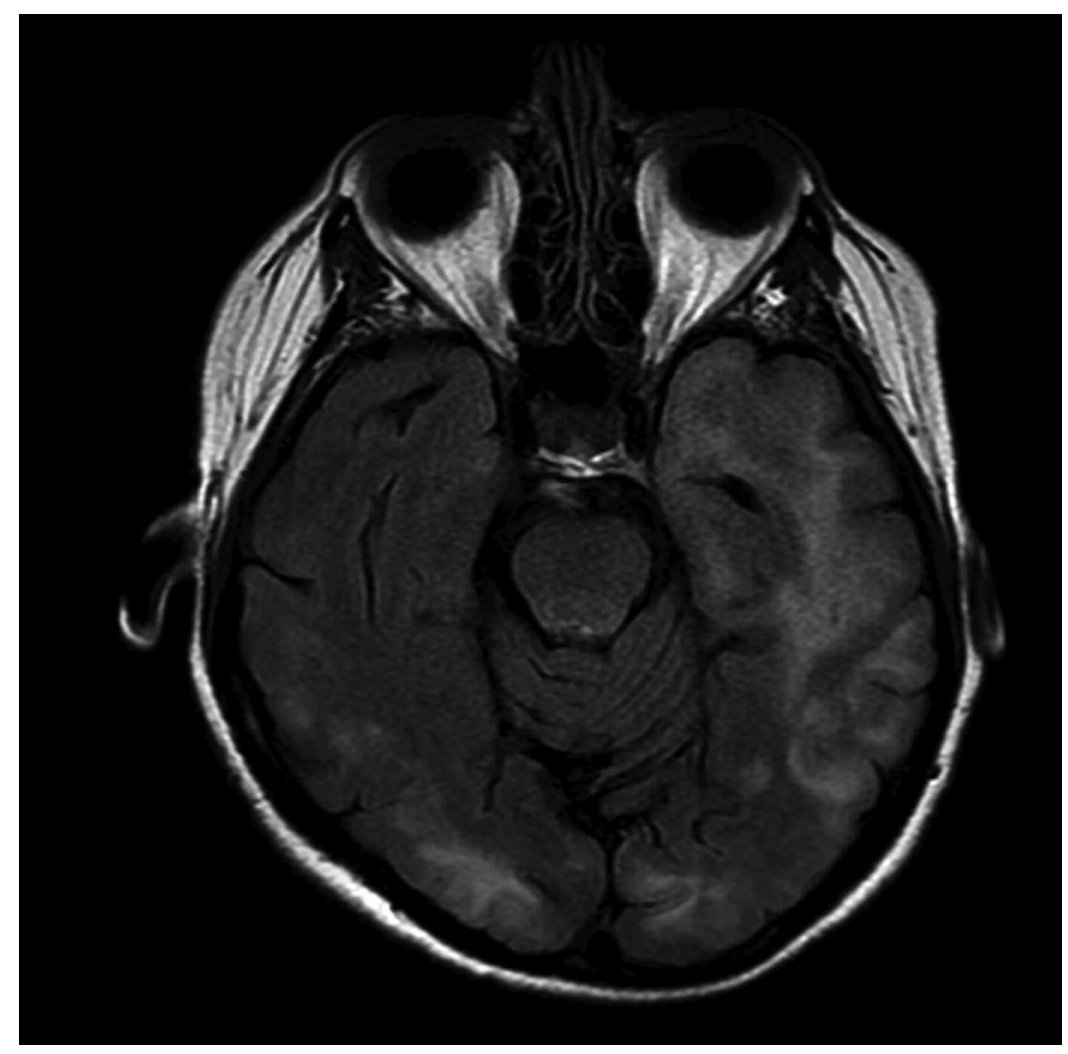

Figure 2. MRI done a week later showed increased white matter hyperintensities on FLAIR. MRI: magnetic resonance imaging; FLAIR: fluid attenuated inversion recovery.

SLE itself and immunosuppressive agents ${ }^{5}$, including MMF, could have predisposed this patient to PML, but because of the temporal evolution, we believe that belimumab was the principal contributor. Clinicians should be aware of the risk of PML in patients using belimumab.

\section{REFERENCES}

1. Molloy ES, Calabrese LH. Progressive multifocal leukoencephalopathy associated with immunosuppressive therapy in rheumatic diseases: evolving role of biologic therapies. Arthritis Rheum 2012;64:3043-51.
2. Hahn BH. Belimumab for systemic lupus erythematosus. N Engl J Med 2013;368:1528-35.

3. Fredericks C, Kvam K, Bear J, Crabtree G, Josephson S. A case of progressive multifocal leukoencephalopathy in a lupus patient treated with belimumab. Lupus 2014;23:711-3.

4. Wallace DJ, Navarra S, Petri MA, Gallacher A, Thomas M, Furie $\mathrm{R}$, et al. Safety profile of belimumab: pooled data from placebo-controlled phase 2 and 3 studies in patients with systemic lupus erythematosus. Lupus 2013;22:144-54.

5. Nived O, Bengtsson AA, Jönsen A, Sturfelt G. Progressive multifocal leukoencephalopathy - the importance of early diagnosis illustrated in four cases. Lupus 2008;17:1036-41. 